\title{
Ficção-Fricção: Operando Aberturas de Ar e Produzindo Educação Matemática de/na/com/para Educação do Campo
}

\section{Fiction-Friction: Operating Air Openings and Producing Mathematical Education with/from/with/for Field Education}

\author{
Ronilce Maira Garcia Lopes ${ }^{\text {; }}$ Diego de Matos Gondim ${ }^{\mathrm{b}}$ \\ a Departamento de Educação Matemática, Universidade Estadual Paulista, Rio Claro, Brasil - romagalo@gmail.com \\ b Departamento de Educação Matemática, Universidade Estadual Paulista, Rio Claro, Brasil - gondiminit@ hotmail.com
}

Palavras-chave:

Educação matemática.

Educação do campo.

Ficção. Filosofias da diferença. Escola do campo.
Resumo: Este artigo tem como escopo entranhar nos estranhamentos de uma dissertação intitulada: Histórias de uma pesquisa(dora) em uma escola do campo com professores que lecionam Matemática. Para tanto, o artigo fricciona a ficção de algumas partes da dissertação: no primeiro ato tem se quatro episódios com intervenções e no segundo ato, apresentam-se documentos sobre Educação do Campo e discute-se como a Educação Matemática tem se friccionado na/de/para/com a Educação do Campo. Desse modo, os fios puxados aqui entranham no emaranhado de uma Dissertação que encontra na ficção uma maneira de friccionar alguns acontecimentos/estranhamentos vivenciados por uma pesquisa(dora) nos territórios existenciais de vidas.

\section{Keywords:}

Mathematics education.

Field education. Fiction.

Philosophies of

difference. School of the field.
Abstract: This article has as scope to entangle in the strangeness of a dissertation titled: Stories of a (re)research in a school of the field with teachers who teach Mathematics. To do so, the article rubs the fiction of some parts of the dissertation: in the first act there are four episodes with interventions and in the second act, documents are presented on Field Education and it is discussed how Mathematics Education has rubbed itself from/with/with/for Field Education. In this way, the strands drawn here are entangled in the tangle of a Dissertation that finds in fiction a way of rubbing some events/strangles experienced by a (re)search in the existential territories of lives. 


\title{
In-trodução
}

\author{
Estranh-ar \\ Entranh-ar \\ Entra-n-h-ar \\ Est-r-a-n-h-ar \\ E-n-t-r-a-n-h-ar \\ Estranh-ar-Entranh-ar \\ Processos de estranhamentos produzem entranhamentos \\ arranhando nossa alma \\ Entra-h-h-ar \\ produzindo modos de experimentar \\ a vida vi-vendo em nós \\ a vida sendo produzida em nós \\ Há vida em nós \\ Vida vi-vendo nós \\ Vida sendo nós \\ Vida estranhando nós \\ Vida entra em nós \\ Vida em nós \\ Aqui, um convite para fiar nós \\ Nósoutros
}

“'Iniciar' deriva do verbo latino initiare, um composto do verbo ire, 'ir', 'marchar', de modo que, com o acréscimo da proposição in-, indica 'entrar' e, de modo absoluto, "começar"” (CASLELLO; MARSICO, 2007, p. 42, grifos dos autores). Entrar estranhando uma escrita. Entrar em escrita estranhada. Iniciar entrando em um composto, indo, engendrando(-si) em produções de subjetividades, num emaranhado de tramas que compõem vida(s). Friccionando linhas, umas nas outras; com outras; para outras... Produzindo ficção na/com/em fricções, tensões de vidas que saltam de uma pesquisa de Mestrado. Aqui, propomos um exercício de ficção friccionando episódios que compõem uma pesquisa de Educação Matemática que se faz de/na/com/para uma Educação do Campo. Essas linhas compõem, tão somente, um convite 'mal' feito a você - caro leitor ${ }^{1}$ - para estranhar quatro episódios de Lopes (2016); multiplicidade de afectos que nós criam. Histórias de uma pesquisa(dora) que (des)dobra de/na/com/para Educação do Campo. Um emaranhado de linhas que compõem Educação Matemática e Educação do Campo e movimentos de pesquisa(doras) e constituição de um plano de imanência e... produzir histórias.

Para Souza e Silva (2015, p. 57) “narrar, contar histórias é algo comum, natural aos seres humanos. Portanto, para pensar sobre suas potencialidades, é necessário, inicialmente, um exercício de estranhamento". Estranh-ar. Entranh-ar. Entr-ar. Produzir vida(s) com entradas de $a r$. Afirm-ar potências de vida(s) com afectos que pedem passagem, produzindo corpo(s). Produzir histórias com estranhamentos. Estranhar episódios que compõem uma

\footnotetext{
${ }^{1}$ Não sei de onde você vem e muito menos de onde eres, não me importo. Um artesão, ao fiar uma trama de linhas - sejam quaisquer as cores - ele fia com todo o corpo. Todo o corpo vai se enrolando, misturando e combinando movimentos, com todas as linhas. Aqui, te faço um pedido: que me leia com todo o corpo, friccionando movimentos no ato da ficção aqui operada.
} 
pesquisa(dora) em Educação Matemática. Entrar nos jogos de ficção da pesquisa(dora) de Lopes (2016), friccionando episódios que narram a processualidade de uma investigação.

Neste artigo, propomos ao leitor exercitar conosco uma entrada em Lopes (2016) e produzir (des)dobramentos em/na/com/para Educação Matemática e Educação do Campo. $\mathrm{O}$ ato de contar histórias é um ato de estranhar a si mesmo. Um convite a entr-a-n-h-ar nessa complexidade de sujeitos, onde sangue e tinta e realidade e imaginação e passado e presente e futuro e... coengendram-se. Produzir ficção com fricções junto a episódios que compõem a pesquisa(dora) de Lopes (2016). Caminhando com seus trieiros ${ }^{2}$, produzindo outros, nós em/na/com/para Educação Matemática e Educação do Campo. Compondo histórias que vão constituindo(-se) com as marcas que atravessam e produzem corpo(s), onde tinta e papel, carne e osso - que compõem uma pesquisa(dora) - afirmam vida(s). Vidas que se tecem juntas, da Educação Matemática e da Escola Municipal Dom Bosco - Polo e Extensões: Cirilo Anoena da Costa $^{3}$, chamada por Lopes (2016) de, apenas, escola Dom Bosco. Um convite para experimentar episódios de uma escola.

\section{Entrando na ficção dos episódios de uma pesquisa(dora)}

\section{Episódio 1: Um dia entre tantos}

Dia 26 de fevereiro de 2015. São, aproximadamente, 11h 20 min. O local é em frente à Secretaria de Educação do Município. Uma pesquisa(dora), professores(as), diretora, coordenadora, pais, alunos, todos à espera do ônibus que os levará à escola. Uma chamada Dom Bosco. Uma escola com aulas, apenas, no período vespertino.

Enquanto espera, nossa pesquisa(dora) pensa no quanto estava acostumada a ver os ônibus parados naquele local à espera dos alunos. Ela agora está vivenciando o contrário, isto é, está à espera de um ônibus que os levará para a escola. Enquanto espera, outros ônibus chegam e saem. Levam alunos de volta para as suas casas ou os trazem para a escola. E aqui, entre essa história e outras, acontece aquele momento de flashback, onde outras histórias atravessam a que aqui está se compondo.

Esper-ar... Nossa pesquisa(dora) esperou, em frente à Secretária, a chegada do ônibus. Esperou novamente dentro do ônibus. Ela já sabe, por experiência, que essa espera dentro do ônibus varia entre cinquenta minutos a uma hora e vinte minutos, o que depende da situação da estrada para chegar à escola. Esse é o tempo que se leva para percorrer $35 \mathrm{~km}$ da cidade até

\footnotetext{
${ }^{2}$ Segundo a autora, trieiros remete a um caminho estreito, aberto por passagens sucessivas no meio do mato, como uma trilha, um passadiço. Cabe ressaltar que esta expressão é comumente utilizada pelas pessoas do Estado do Mato Grosso do Sul. Acrescentaríamos, ainda, que um trieiro é sempre um possibilidade de entrada com múltiplas saídas, visto que, ao entrar, você pode seguir o caminho já feito ou criar outros caminhos mata à dentro.

${ }^{3}$ A escola Dom Bosco se situa na zona rural do Munícipio de Inocência no Estado do Mato Grosso do Sul
} 
a escola, situada na zona rural do Município. Uma pesquisa(dora) se constitui com a espera. Uma espera de múltiplas entradas e saídas.

Aqui está ela, numa estrada de terra castigada pela chuva e pelo sol. Castigada pelo movimento intensivo dos caminhões carregados de gados que aqui passam constantemente. Castigada pelos ônibus que transportam alunos e também professores. Castigada por ônibus que levam trabalhadores às plantações de Seringa e de Eucalipto.

Nessa estrada - em épocas de chuvas - há barro, poças, carros atolados e, em épocas de seca, há poeira. Muita poeira. Com essas estradas, um plano de uma escola do campo se constitui - uma educação do campo. Estradas que marcam alunos, tempos, espaços, terra... Marcas do percurso percorrido; poeira ou lama nas roupas. Entradas na escola e chegadas em casa marcadas pelo tempo do ônibus na estrada. Tempo composto por outros tempos: tempo de espera; espera por um transporte amigo que ajude desatolar o ônibus do barro. Por vezes, os alunos não vão à escola, pois quando o ônibus é desatolado já é hora de voltar para casa. Os alunos chegam. Com uma roupa sobre a outra, enrolados em toalhas, tentam vedar a poeira para chegar limpos à escola.

Nessa situação, nossa pesquisa(dora) questiona: como esses professores estão operando com essa realidade, como produzem (com) essa realidade? Como uma escola do campo funciona e produz suas singularidades? Como acontecimentos são experimentados na Escola Dom Bosco? Que acontece quando nada parece estar acontecendo na Escola Dom Bosco? O que acontece nas trincheiras dessas experimentações?

\section{Episódio 2: Quem?}

Neste mesmo dia - além de todas sensações - há fofocas, burburinhos, há uma multiplicidade de coisas acontecendo que minhas narrativas jamais seriam capazes de esgotar os acontecimentos - e nem planejo isto. A professora que lecionava Geografia e Produção Interativa não veio à escola. Isto é algo inesperado. Coisas in-esperadas acontecem em uma escola do campo. Uma pesquisa(dora) é produzida nos instantes in-esperados de uma escola do campo. Uma escola do campo, há falta de professores. Eles não conseguiram um professor para substitui-la. Os alunos, agora, estão com "aula vaga".

Esta falta produziu grande movimentação na escola. A professora havia conseguido 40 dias de atestado médico. Uma solução imediata foi tomada: a contratação de uma professora substituta. Contrataram uma professora. Ela acaba de chegar ao município e ainda não conhecia a escola. Uma professora que lecionava no Centro Educacional de Inocência (CEI) Professor Olivalto Elias da Silva, no período matutino e completava a sua carga horária no período vespertino. Dois fatos possibilitaram à professora assumir as aulas de Geografia e Produção Interativa: $1^{o}$ ) os professores do CEI estavam em greve; e $2^{\circ}$ ) o período de trabalho 
da Escola Dom Bosco é o período vespertino. Uma escola está acontecendo. Juntos estamos criando a espacialidade e a temporalidade de uma escola em constante movimento. Uma pesquisa(dora) se faz...

Durante uma semana tudo ocorreu bem. Um boato chacoalha o campo: a greve deveria ser interrompida - por ordens judiciais. Uma greve rompida, um rompimento na greve, uma greve em rompimento - in-ter-rompida. Uma tensão nos corredores, no ônibus, na escola, neste lugar que você está entrando conosco. A professora que leciona Inglês avisa que não continuará a dar aulas na escola. $O$ in-esperado compõe esta escola. Ela estava de volta ao município depois de um tempo morando em outra cidade. Estar de volta ao município, para ela, se caracterizava na possibilidade de uma oportunidade de emprego fixo na cidade. Fixar(-se) na cidade. A professora conseguiu apenas essas aulas de Inglês na Escola Dom Bosco e este foi um dos motivos pelos quais ela decidiu retornar, deixar a escola - mais uma vez a escola ficava sem professor. Na busca por soluções imediatas pela falta de professores, as medidas que são tomadas produzem tensões na escola. Uma escola é produzida por tensões; tensões em uma estrada, tensões em entradas e saídas, tensões que compõem a trama de uma escola do campo. "Soluções" são tomadas. Que seria uma escola sem soluções, sem resultados in-esperados? Uma escola problema?! Escola problemática?! Escolas-soluções, escolas-axiomas. Escola-problema, escola-acontecimento. Escola-vidaempoeirada, escola-vida-enlameada Tempo de espera. Espera o ônibus, chegar, sair, parar; um tempo que atravessa os currículos, que os fazem funcionar numa lógica que não é a do sistema. Um tempo que vira ao avesso a lógica sistemática de uma escola-campo. Tempo de sair, tempo de ficar. Tempo (de espera).

Uma nova solução referente à disciplina de Inglês é encontrada: a professora que leciona no $5^{\circ}$ ano do Ensino Fundamental como titular - com formação em Letras e habilitação em Inglês - deixa a turma do $5^{\circ}$ ano para lecionar a disciplina de Inglês. Tal decisão foi baseada na tentativa de evitar que tivessem mais professores lecionando em áreas distintas de sua formação. Isto mesmo: professores lecionando em áreas distintas ou similares a sua formação é algo bastante comum na escola. Nossa pesquisa(dora) experimentou e experimenta, aqui, diversos modos de ser professor. Professores de História formados em Geografia; formados em Letras lecionando Artes e Filosofia; engenheiro lecionando Matemática; matemáticos lecionando Física; biólogos atuando em Química; e por aí vai.

Conseguiram uma professora de Inglês, porém nosso $5^{\circ}$ ano está sem professor titular. $\mathrm{Na}$ Secretaria de Educação, uma professora havia dado seu nome caso precisassem de professores para lecionar Ciências. A escola não precisa de professor de Ciências - para sanar essa atuação de professores em áreas distintas de sua formação e sem muitos professores disponíveis - entra em contato com ela, convidando-a para lecionar Ciências na escola. Um 
convite, a entrada de uma nova professora. Um plano subjetivo, com múltiplas linhas de subjetivação, vai compondo a trama desta escola. Entre tensões e intensões. Com o aceite do convite, a professora - que até então lecionava Ciências na escola sem formação na área assumiu a titularidade do $5^{\circ}$ ano. Ela havia feito Magistério e Pedagogia. A professora, no entanto, por motivos pessoais, não se sentiu à vontade com a mudança. Uma turma, alunos do $9^{\circ}$ ano do Ensino Fundamental se incomodam. Um movimento produzido por in-cômodos. Incômodos nos cômodos que compõem a arquitetura de uma escola. "Ela era nossa amiga", diziam eles. O rompimento de uma amizade na sala de aula. O inter-rompoimento de uma multiplicidade de afetos ${ }^{4}$. O entre-linhas que produzem incômodos de afectos que pedem passagens e criam afetos, sentimentos. Entre-sentimentos, uma sensação é produzida por afectos. Afectos deslocam os sentimentos cristalizados. Rompendo linhas duras e produzindo movimentos, micro-revoluções - eles queixam(-se).

Enquanto isto, a professora continuava dando aulas de Geografia e Produção Interativa na escola três dias da semana e, com a inter-rupção da greve, voltou a lecionar no CEI no período matutino. Em um dia da semana, no período vespertino, dava aulas no CEI completando sua carga horária, e em outro dia fazia faculdade na cidade vizinha. Ela necessitava estar na cidade às 17 h e 30 min e este era o horário em que o ônibus saía da escola, assim, não conseguia ir para a Escola Dom Bosco nestes dias. Outra professora, no entanto, a substituía. Uma substituição. Substituir o outro. Subjetividades que atravessam. Ela dá suas aulas seguindo o planejamento da outra professora. Como subjetividades atravessam planejamentos? Como planejamentos atravessam subjetividades? Nas linhas da outra, uma professora se compõe. Uma aula acontece. Nas aulas da substituição, uma professora um planejamento atravessa, a outra atravessa... Outros atravessam nós, compõem nós nósoutros.

O atestado da professora de Geografia e Produção Interativa chegou ao fim e ela voltou com outro atestado, com este ela não voltará a lecionar na escola. A professora que a substituía, então, abre mão de suas aulas no CEI e assume as aulas na Escola Dom Bosco. O desconforto entra em cena. $\mathrm{O}$ desconforto da professora que assumiu a titularidade do $5^{\circ}$ ano. Uma professora que, entre outras formações, também é pedagoga, assume a titularidade do $5^{\circ}$ ano. A disciplina de Geografia e Produção Interativa ainda ocupa um espaço vazio no tempo. Um vazio que busca preenchimento. Vazio agora preenchido. A professora que havia assumido a titularidade do $5^{\circ}$ ano, que lecionava Ciências sem formação, está lecionando

\footnotetext{
${ }^{4}$ Em linhas gerais, os afetos estão na dimensão das paixões, dos sentimentos, enquanto que o afecto está na dimensão da efetuação de um corpo, ou seja, uma afecção. Um corpo é criado no plano das afeções, em sua imanente efetuação. Segundo Deleuze (2002, p. 56) a "afecção remete a um estado do corpo afetado e implica a presença do corpo afetante, ao passo que o afeto remete à transição de um estado a outro, tendo em conta a variação correlativa dos corpos afetantes".
} 
Geografia também sem formação. Escola-solução. Entre os vazios no tempo e a sistemática de uma escola-solução, uma escola-problema é produzida. Vidas afirmam(-se) em um espaçotempo movimentado por tensões entre o vazio e o preenchido. Uma escola acontece. Um planejamento é atravessado. Professores se compõem.

No fim das contas, o $5^{\circ}$ ano ficou com uma professora que tem formação em Pedagogia - depois de ter três professoras titulares em um período de um mês -, a professora que assumiu a disciplina de Inglês tinha formação específica e a professora da disciplina de Ciências também tinha formação na área. Desse modo, apenas a disciplina de Geografia e Produção Interativa ficou com uma professora s(em) formação. Ufa, fiquei sem folego. É complexo. Embananei-me um pouco com as idas e vindas, com os vazios do tempo e com o tempo esvaziado. O entre uma escola-axiomática e uma escola-problemática. Histórias vão fiando(-se) e produzindo uma pesquisa(dora).

Entre tantos acontecimentos, a pesquisa(dora) é atravessada; e como não ser?! Apenas se fechasse os olhos (será?!). Nossa pesquisa(dora) também é professora e, conhecendo tal realidade, imagina(-se) nesta situação, pois em outras circunstâncias ela havia vivenciado enquanto professora itinerante ${ }^{5}$ da Escola Estadual e também como professora substituta, tanto no CEI quanto na Escola Estadual. Entre as afetações, perguntamos: como esses professores produzem(-se)? Como eles percebem(-se) e operam(-se) junto a esses acontecimentos? Como inventa (-se) junto a essa realidade? Como a escola funciona currículo, sala de aula, professores saindo e entrando e...?

\section{Episódio 3: Quatro paredes e seus segredos}

Multisseriada, uma sala com várias séries. Nesta escola, até 2013, era comum salas multisseriadas por distintos motivos, um deles - e talvez o mais importante - é a infraestrutura da escola. Apesar de, em 2014, ter sido inaugurado um prédio novo, ainda se mantém uma sala multisseriada na escola.

Temos um prédio construído com uma forma, um modelo, feito em uma fôrma. Uma fôrma-prédio que deixa nas bordas o campo. No entanto, o que excede nas bordas da fôrmaprédio, de uma arquitetura (des)planejada, atravessa-o no meio em acontecimentos. Produções de subjetividades, re-existências de um plano existencial que afirma sua potência nos modos de ser-no-campo. No prédio novo, temos: salas reorganizadas, remanejadas, operando multisséries. Porém - dentro desse organismo multisseriado - re-existem multiplicidades. Multiplicidades de vidas sendo afirmadas; vidas desejantes, territórios re-existenciais. Um $1^{\circ}$

\footnotetext{
${ }^{5}$ Professor Itinerante é aquele que leciona para alunos que estejam impossibilitados de ir à escola, por um período longo, por diferentes motivos, de modo que, professores itinerantes são contratados para atender esses alunos em sua casa.
} 
ano e um $2^{\circ}$ ano do Ensino Fundamental re-existem com multiplicidades operadas em multisséries.

Nossa pesquisa(dora) está em sala de aula, junto às multiplicidades, operando com territórios re-existenciais, produções de subjetividades de alunos que re-existem dentro de uma fôrma-prédio com singularidades que excedem a fôrma, afirmam vidas. Ela opera naquelas inter-rupções do tempo. Do tempo que um afastamento médico cria, dos tempos de espera. No tempo de espera, re-existências são afirmadas. Os incômodos vão amenizando-se e uma produção sentimental entra em cena mudando o jogo de poder. Entra em cena com coleções de abraços ao chegar à escola e com um "tia, me ajuda aqui?" e "tia, como faz isso?" e "tia, você prendeu o cabelo com a caneta?" e... Quando o jogo de poder é reconfigurado quer dizer que as forças se redistribuíram nesse espatium continnum que são os territórios existenciais.

O que excede da fôrma é também operado em suas frestas, gretas e reentrâncias. Nos corredores, uma educação acontece. Uma educação em movimento junto à pressa dos professores de uma sala à outra, aos pega-pegas das crianças que logo são interrompidos... Uma educação acontece, está em movimento. No ônibus, uma educação acontece... o que trans-borda nas bordas ganha movimento em seus limites e escorre, es-corre. A isto, dou o nome de transcendência na imanência. Trans-borda, transcendendo na imanência dos movimentos dos professores nos corredores, no tempo de espera que inter-rompe a linearidade temporal. Assim, entre acontecimentos e afetações, nossa pesquisa(dora) experimenta uma escola em acontecimentos, com acontecimentos. Alunos e professores reexistindo e criando territórios re-existências. Operando lugares, fazendo funcionar uma forma-escola para além de seus limites, produzindo o ilimitado, subjetividades. Produzindo, na espera, na inter-rupção do tempo, um instante, movimentos que arrastam as bordas para um meio chamado imanência, fluxos sensíveis do desejo de re-existências.

Re-existiam com livros didáticos doados. Re-existiam uma escola (do/no/com/para) campo. Produziam uma educação do/no/com/para campo. Uma educação-movimento que acontece nas trans-bordas de uma fôrma-Educação-do-Campo. Escola Dom Bosco, uma escola de re-existências. Na fala dos alunos, encontros e desencontros. No chão, junto a pisadas de cavalos e bois e arrastados de enxadas e tratores e... se misturam aos verdes do campo, à terra vermelha batida, ao pôr do sol multicolorido. Uma escola re-existe. Nossa pesquisa(dora) opera assim, junto a territórios re-existenciais, com entrâncias e reentrâncias, fluxos contínuos de uma educação em movimento...

Os fluxos dessas aulas não eram povoados apenas por equações do $2^{\circ}$ grau e sequer das noções básicas da Aritmética que, comutativamente, associavam unidades numéricas. As aulas de nossa pesquisa(dora), compõe as tramas de si e do campo que escapavam do múltiplo 
distributivo produzindo multiplicidades, a composição. Se existe uma regra na produção de territórios re-existenciais, eu chamaria de camposição: composições de forças ativas que afirmam vidas do/no/com/para campo. Um campo-atividade que produzia aulas com cavalos e calças de couro e esporas e bois e montarias e bezerros e... livros didáticos doados falam de prédios, de comércio, de roupas em vitrines de boutique.

Experimente você, caro leitor. Venha, junto a mim, estranhar a escrita deste artigo com territórios re-existenciais de uma escola.

\section{Episódio 4: Equações do $1^{\circ}$ grau $-8^{\circ}$ ano do Ensino Fundamental: estranhamentos e produção de territórios re-existenciais de uma camposição}

Professor: Quando vocês vão crescer?

- Aluno: Mais? Já estou quase do seu tamanho, prossor.

- Professor: Não me refiro a isso. Estou falando de conhecimento. Não pensam em estudar? Em ser um advogado, médico, professor, engenheiro?

- Alunos: Não.

- Aluno: Minha vida é na fazenda.

- Aluno: É mesmo, prossor. Eu gosto de fazenda, de mexer com vaca, com trator.

- Professor: Vocês vão fazer isso o resto da vida de vocês? Mas e a tecnologia, os tratores estão cada vez mais equipados?

- Aluno: Prossor prefiro a enxada a ficar aqui sentado sem fazer nada. Trator é fácil.

É só pegar o prumo dele e já é.

- Aluno: Tecnologia é com a gente, né? Prefiro carpi o quintal de casa a vim pra cá.

O tempo que fico aqui dá pra mim carpi cinco vezes o quintal de casa e ainda fico de boa.

- Professor: Vão acabar com as mãos. Vocês sabem que o estudo é importante, ninguém tira isso de vocês.

- Aluno: Ah! Prossor meu pai tem a $4^{\mathrm{a}}$ série, meu vô nem isso, eu tô no $8^{\circ}$ ano. Já tá bom.

- Aluno: A gente sabe o que tem que saber já. Se eu falar pro meu pai que não vou vim mais pra escola, ele vai dizer que tudo bem.

- Professor: E vão trabalhar?

- Aluno: É muito melhor do que ficar aqui.

- Aluno: É isso que sei fazer, é isso que gosto de fazer.

Entre quatro paredes de uma sala de aula, territórios re-existenciais são produzidos trans-bordando as margens "bem" delimitadas de uma fôrma-prédio. Uma educação acontece no que excede estas bordas, no liame que separa o dentro e o fora, o urbano e o rural, a forma e o marginal, uma camposição que fia linhas de subjetividades entre a organização binária da Educação do Campo. Uma camposição que não sonha um futuro médico, advogado, engenheiro, professor... Uma camposição quintal, enxadas, trabalho, onde basta o $8^{\circ}$ ano. No quintal, o liso e o estriado coexistem... alisam no varrer e no carpir, estriam no plantar. Práticas coexistentes que produzem territórios re-existenciais. Uma educação acontece transbordando a obrigatoriedade da Educação do Campo, transcendendo a promessa de um futuro de "sucesso".

Equações do $1^{\circ}$ grau remete a uma aula de Matemática que foi inter-rompida por algumas impertinências colocadas na relação entre professor e alunos. De um lado, o 
professor provoca os alunos a refletirem sobre suas condições e possibilidades de ser em um futuro. Ele diz: "não pensam em estudar? Em ser um advogado, médico, professor, engenheiro?". De outro lado, os alunos provocam o professor - em um tom 'quase' satírico ao dizerem "mais? Já estou quase do seu tamanho, prossor" - a se deslocar de uma necessidade própria do professor para uma "realidade" no/do campo. A impertinência posta nesta relação, provoca, no lugar do aprender as equações do $1^{\circ}$ grau que era o plano de aula, um contato corpo-a-corpo entre o professor e os alunos. Eles provocam: "minha vida é na fazenda [...] Eu gosto de fazenda, de mexer com vaca, com trator". Essa relação expressa um embate entre corpos. Corpos sonhados e corpos imanentes... Corpos que insistem!

Que acontece em uma aula de Matemática? Equações de $1^{\circ}$ grau?! Que passa entre as carteiras de uma sala de aula onde se deseja ensinar equações de $1^{\circ}$ grau? Neste episódio, acontece um embate, uma batalha entre-mundos, entre corpos que sonham e corpos que vivem a imanência de seus desejos na profundidade da pele. Pele-campo. O campo é uma pele de re-existências, corpos que insistem em uma estética de vida que carpi o quintal, que trabalha... "É isso que sei fazer, é isso que gosto de fazer".

\section{Operando linhas duras até que flexíveis sejam: aberturas para produzir linhas de fuga}

Aqui, tentaremos compreender melhor os trieiros por onde essas histórias se entrecruzam. O primeiro discurso é de uma tal de Lei de Diretrizes e Bases da Educação (LDB), lei 9.394/1996. Ela é um marco e uma conquista para a Educação e, claro, para a Educação do Campo. Tomamos a LDB como um marco para essa discussão e, a partir dela, começamos uma conversa com os discursos de tinta e papel sobre a Educação do Campo.

A LBD - em seu artigo 28 nos incisos I, II e III - discute sobre a Educação Básica do Campo e reforça suas especificidades, quais sejam:

\footnotetext{
Na oferta de educação básica para a população rural, os sistemas de ensino promoverão as adaptações necessárias à sua adequação às peculiaridades da vida rural e de cada região, especialmente:

I - conteúdos curriculares e metodologias apropriadas às reais necessidades e interesses dos alunos da zona rural;

II - organização escolar própria, incluindo adequação do calendário escolar às fases do ciclo agrícola e às condições climáticas;

III - adequação à natureza do trabalho na zona rural. (BRASIL, 1996, p. 28, grifos nosso).
}

Para dar conta dessas especificidades, recomenda-se que as escolas elaborem suas propostas pedagógicas de modo a contemplar as necessidades dos estudantes do campo e ainda diz que o calendário escolar deve ser adequado à natureza do trabalho do campo, no qual a escola está inserida. Cada escola, então, deve pensar sua proposta e seu calendário junto às singularidades do campo. Perguntas simples para começar a pensar, talvez, sejam: qual é a época de plantio e colheita? Quando é a estação das chuvas? 
No entanto, vale ressaltar o que, antes do artigo 28, é discutido nos artigos 23 e 26. Estes, por sua vez, abrem a possibilidade de definir diretrizes operacionais voltadas para as escolas do campo. Com essa abertura, a Resolução do CNE/CEB $n^{\circ} 1$ dispõe sobre orientações para garantir a universalização do acesso e a permanência da população do campo em todas as etapas e modalidades da Educação Básica.

Nesta resolução, há um discurso que vem reforçando a importância de as escolas do campo organizarem e pensarem suas propostas pedagógicas de modo que suas atividades fossem desenvolvidas com a participação da comunidade, gerando assim um processo chamado de gestão democrática na escola. A resolução, também, discute sobre a formação inicial e continuada de professores, ressaltando que tais formações devem abordar em seus cursos as especificidades do campo.

Outro papel importante para a Educação do Campo é encontrado na Resolução $\mathrm{CNE} / \mathrm{CEB} \mathrm{n}^{\mathrm{o}}$ 2, que estabelece as diretrizes complementares para o desenvolvimento de Políticas Públicas para a Educação Básica do Campo.

A Educação do Campo compreende a Educação Básica em suas etapas de Educação Infantil, Ensino Fundamental, Ensino Médio e Educação Profissional Técnica de nível médio integrada com o Ensino Médio e destina-se ao atendimento às populações rurais em suas mais variadas formas de produção da vida - agricultores familiares, extrativistas, pescadores artesanais, ribeirinhos, assentados e acampados da Reforma Agrária, quilombolas, caiçaras, indígenas e outros.

Há, no entanto, algo que nos incomodam nessa Resolução, em seu artigo $3^{\circ}$. As diretrizes complementares orientam que o atendimento da Educação Básica do Campo deve ser o mais próximo possível da comunidade de moradia dos alunos, dando total liberdade para as escolas criarem critérios para a nucleação e, também, para estabelecer o modo como o atendimento por meio do transporte escolar ocorrerá. A questão é que não é em todas as regiões que se tem comunidades, pois - sobretudo hoje - as grandes fazendas predominam e o povo do campo vive isolado, distante da cidade e até mesmo dos demais povos do campo. Me parece muito importante a escola poder se organizar nessa questão de localização e locomoção, pois ainda há muitas crianças que passam horas e horas dentro de um ônibus.

Outro discurso de papel é o da Resolução CNE/CEB nº 04/2010, que diz das Diretrizes Curriculares Nacionais de Educação Básica. Em sua seção IV, a Resolução discute sobre a Educação do Campo. O artigo 35, que deriva da LDB, juntamente com o artigo 36, trata sobre a identidade da escola do campo. Como se dá? Como se constitui essa identidade da escola do campo? Esse documento propõe que as escolas organizem suas propostas pedagógicas contemplando toda a diversidade que as cerca, seja social, cultural, política, econômica, gênero, geração e etnia. Além disso, a Resolução discute também as formas de organização e metodologia. 
Formas de organização e metodologia pertinentes à realidade do campo devem ser acolhidas, como a pedagogia da terra, pela qual se busca um trabalho pedagógico fundamentado no princípio da sustentabilidade, para assegurar a preservação das vidas das futuras gerações, e a pedagogia da alternância, na qual o estudante participa, concomitante e alternadamente, de ambientes/situações de aprendizagem: o escolar e o laboral, supondo parceria educativa, em que ambas as partes são corresponsáveis pelo aprendizado e pela formação do estudante (BRASIL, 2010, p. 12).

Vocês conheciam essas pedagogias? Nós não. Achamos que estamos precisando de atualização, pois elas são deveras importantes e deveriam ser de conhecimento amplo. No entanto, vamos ao próximo discurso.

O Decreto n. ${ }^{\circ} 7.352 / 2010$ - que é a Política Nacional de Educação na Reforma Agrária (PRONERA) - define os mecanismos e princípios que buscam a manutenção e o desenvolvimento da Educação do Campo no âmbito das políticas nacionais.

A política de educação do campo destina-se à ampliação e qualificação da oferta de educação básica e superior às populações do campo, será desenvolvida pela União em regime de colaboração com os Estados, o Distrito Federal e os Municípios, de acordo com as diretrizes e metas estabelecidas no Plano Nacional de Educação e o disposto neste Decreto (BRASIL, 2010, p. 1).

Vejam só, é neste documento que se define quem é o povo do campo. "Quem diria, sô? Vê se pode isso? O povo du campo, no papér é: os agricultores familiares, os extrativistas, os pescadores artesanais, os ribeirinhos, os assentados e acampados da reforma agrária, os trabalhadores assalariados rurais, os quilombolas, os caiçaras, os povos das florestas, os caboclos, e outros que tiram da terra sua sobrevivência. Eita, não bastasse dizer quem nóis é, ainda diz quar escola é du campo. Nesse papér, as escolas consideradas escolas du campo são aquelas situadas em ária rurar, seguindo a definição dada pelo Instituto Brasileiro de Geografia e Estatística (IBGE) ou aquelas que se situam em ária urbana, mas que atendam predominantemente o povo du campo". Parece brincadeira, mas não é.

Desculpe-nos pela brincadeira. Brincadeiras à parte, ou melhor, brincadeiras na parte. $\mathrm{O}$ documento também dispõe sobre a formação inicial e continuada para professores. $\mathrm{O}$ Decreto define ainda sobre a oferta das modalidades de ensino para as escolas do campo, referente à Educação Infantil, e à Educação de Jovens e Adultos (EJA). Ademais aborda o acesso à Educação Profissional e ao Ensino Superior. Discute sobre transporte, reformas e ampliação, formação específica de gestores e produção de material didático. E, em um último papel sobre a Educação do Campo, traz o discurso do Programa Nacional de Educação do Campo (PRONACAMPO).

O PRONACAMPO está dividido em quatro eixos e esses são subdivididos em algumas frentes de atuação. O primeiro eixo é referente à "Gestão e Práticas Pedagógicas", o segundo eixo aborda a "Formação de Professores", o terceiro discute sobre a "Educação de 
Jovens e Adultos, Educação Profissional e Tecnológica" e o quarto trata da "Infraestrutura Física e Tecnológica" tendo como objetivo

\begin{abstract}
Disponibilizar apoio técnico e financeiro aos Estados, Municípios e Distrito Federal para a implementação da Política de Educação do Campo, visando à ampliação do acesso e a qualificação da oferta da Educação Básica e Superior, por meio de ações para a melhoria da infraestrutura das redes públicas de ensino, a formação inicial e continuada de professores a produção e a disponibilização de material especifico aos estudantes do campo e quilombolas em todas as etapas e modalidades de ensino (BRASIL, 2013, p. 6).
\end{abstract}

Resumindo, o primeiro eixo tem quatro frentes de atuação. A primeira frente é referente ao Programa Nacional do Livro Didático (PNLD Campo), que busca produzir e disseminar materiais didáticos específicos para os professores e estudantes do campo, de modo que o ensino e a aprendizagem aconteçam de maneira contextualizada.

No entanto, a escola do campo que se mostra em Lopes (2016), é uma escola povoada por livros estrangeiros ao campo. Como retrata sua narrativa, os livros chegam em caixas, sequer pisam os chãos da escola. Ao serem distribuídos, eles só podem ser utilizados em um exercício de sala de aula. Eles não visitam a fazenda, eles não chegam a entrar nos quartos dos alunos, sequer são levados em suas mochilas. Questionamos, que contextualização é essa da qual o PNLD Campo se presta? Livros com desenhos de fazendas, gados etc. são as representações de um campo sem vida, de um campo morto em sua imagem. Como produzir livros (didáticos?!) que expressam um campo que insiste em re-existir?

A segunda frente é o Programa Nacional Biblioteca da Escola (PNBE Temático), que tem como objetivo atender as escolas com uma diversidade de obras, incluindo temáticas como diversidade, inclusão e cidadania. Esta segunda frente, na escola do campo apresentada por Lopes (2016), não opera nem como frente nem como vanguarda. O queremos dizer com isto? O PNBE Temático não existe na Escola Dom Bosco. No entanto, cabe ressaltar que, apesar de não existir um PNBE Temático, que inclui diversidade, inclusão, etc. como frente do Estado, este campo avulta de uma multiplicidade de vidas diversas, que escapam às diversidades. Lá, a diferença está em constante efetuação, que se dá no encontro e não em um PNLD Campo e em um PNBE Temático, se da na imanência de uma vida.

O Programa Mais Educação do Campo é a terceira frente de atuação do PRONACAMPO, que busca contribuir para a estruturação de uma proposta de educação integral nas escolas do campo e nas comunidades quilombolas. Porém, ao mesmo modo que as duas frentes anteriores, o Mais Educação do Campo não acontece. Primeiro porque, para que ele acontecesse, seria necessário, de acordo com sua proposta, estruturar a escola em um tempo integral. A Escola Dom Bosco, no entanto, coloca para nós um tempo da espera, ou seja, a espera pelo ônibus que buscará, a espera pelo ônibus que levará, a espera pela distância a ser percorrida etc. Esta espera, inviabiliza a possibilidade de, na Escola Dom Bosco, 
acontecer esta terceira frente. Segundo, e por último, porque o tempo do campo não é considerado no processo de fazer currículo na Dom Bosco, assim, a proposta desta terceira frente é inviabilizada em sua própria estruturação.

Uma "dimensão" desta terceira frente é a formação (continuada) de professores a partir do Escola da Terra. Nela, busca-se pela melhoria de condições de acesso, permanência à escola do campo e sobre a aprendizagem dos estudantes do campo e quilombolas. Para isso, apoiam a formação de professores para atuarem em turmas multisseriadas nos anos iniciais do Ensino Fundamental, uma realidade das escolas do campo. No entanto, como se pode perceber em alguns episódios aqui apresentados, a formação (continuada) de professores não acontece, haja vista que estes - os professores - estão em um fluxo contínuo de rotatividades (em disciplinas) e mudanças de escolas. Além disto, não há também uma iniciativa do Município para que frentes como estas aconteçam.

Dando continuidade, o segundo eixo é dividido em duas frentes de atuação, sendo elas: Formação Inicial e Formação Continuada de professores. A primeira, que discute sobre Formação Inicial de professores, tem como objetivo incentivar a formação inicial de professores em exercício na Educação do Campo e quilombola. A segunda, sobre a Formação Continuada, busca apoiar: "[...] a formação continuada de professores, gestores e coordenadores pedagógicos que atuam na educação básica nas diferentes modalidades, em escolas do campo e quilombola" (BRASIL, 2013, p. 11).

O terceiro eixo tem duas frentes de atuação. A primeira frente, referente à EJA Saberes da Terra, objetiva proporcionar a escolaridade de jovens e adultos junto a um projeto de desenvolvimento sustentável do campo. A segunda frente busca oferecer oportunidades a jovens e trabalhadores do campo por meio de ampliação da Rede Federal Profissional e Tecnológica ofertando cursos de formação inicial e continuada por meio do Programa Nacional de Acesso ao Ensino Técnico e Emprego (PRONATEC Campo).

O último eixo atua em quatro frentes. A primeira frente de atuação é referente à Construção de Escolas, cujo objetivo é dar apoio técnico e financeiro para realização de melhorias na infraestrutura das escolas, de modo que isso possibilite também a oferta de atividades pedagógicas, profissionalizantes, culturais, esportivas e até mesmo alojamentos. A segunda frente, Inclusão Digital, busca nas escolas do campo o uso pedagógico da informática oferecendo recursos, tais como computadores, recursos digitais e conteúdos educacionais. A terceira frente é o Programa Dinheiro Direto na Escola (PDDE Campo), que visa encaminhar recursos financeiros de custeios e de capital a escolas públicas localizadas no campo. Sua última frente é o PDDE Água e Esgoto Sanitário - que destina recursos financeiros de custeio e de capital às escolas do campo e quilombolas - objetiva garantir abastecimentos de água e esgoto sanitário de formas adequadas às unidades escolares. 
A frente Construção de Escolas aconteceu na Escola Dom Bosco possibilitando a existência de um ensino no campo, porém, as demais frentes se perderam no caminho. Por exemplo, para cumprir a "efetivação" da frente Inclusão Digital, foi realizada a instalação dos cabos para viabilizar o acesso à internet, no entanto, esta rede nunca foi ativada e, da gestão ao alunos, ou dos alunos à gestão, nunca houve acesso à internet.

Questionamos: qual frente ocupa estas frentes do PRONACAMPO? Estaria elas na frente da Escola Dom Bosco?! Estas frentes ocupam a frente de uma escola do campo?!

\section{Na mesa com Línlya: tecendo fios e puxando outros}

"Quando eu vou, às vezes, dar um exemplo, eu começo a citar boi, hortaliças, verdura". "Vamos aos saberes locais, porque eles também foram acumulados pela humanidade". "Matemática é Matemática, ou tem Matemática do campo?" "A escola pode ajudar nessa formação deles, ajudar na família, no cultivo, no plantio”. Línlya chega a essas quatro frases em sua tese, após um longo caminho trilhado. O título de sua tese é: "Entendimentos a respeito da matemática na educação do campo: questões sobre currículo" (BARBOSA, 2014).

No entanto, não são frases soltas, são frases que nomeiam suas categorias e que foram proferidas por alguns de seus sete depoentes entrevistados: uma diretora de uma escola localizada em um assentamento rural; uma professora de Matemática de outra escola localizada em outro assentamento rural; uma pesquisadora da área da Educação Matemática que trabalha com a temática da Educação do Campo; uma coordenadora pedagógica de uma escola do Movimento dos Trabalhadores Rurais Sem-Terra (MST); dois pesquisadores da área de Educação que trabalham com a Educação do Campo; e uma moradora de assentamento rural, ex-estudante de uma escola do campo.

Línlya, para percorrer pelos trieiros da Educação do Campo entre a Educação Matemática, também trilhou por anais de um evento - Encontro Nacional de Educação Matemática (ENEM), de uma revista da área - Boletim de Educação Matemática (Bolema) e das dissertações e teses publicadas e disponíveis no nco de Teses da Coordenadoria de Aperfeiçoamento de Pessoal de Nível Superior (Capes). Caminhou, também, por trieiros dos cursos de Licenciaturas em Educação do Campo. Aff, quanta coisa hein? Línlya você pode falar um pouquinho sobre suas categorias?

Claro que sim, com prazer!

"Quando eu vou, às vezes, dar um exemplo, eu começo a citar boi, hortaliças, verdura”. Essa primeira categoria é uma discussão que vai em direção aos conteúdos e métodos do currículo. Nesse sentindo, as discussões partem da ideia de que os conteúdos das escolas do campo devem ser os mesmos das escolas urbanas, mas as maneiras, os métodos de 
se trabalhar, de se alcançar os objetivos podem e devem trilhar por outros caminhos, indicando que a "realidade do aluno do campo" pode ser um ponto de partida para o trabalho em sala de aula.

Esta primeira categoria revela um "esforço" do professor no processo de ensino, o que expressa uma educação para o campo. Como apresentado no episódio 4, na aula de matemática que o professor desejava o ensino de equações do $1^{\circ}$ grau, uma educação para o campo entra em embate (é questionada) com uma educação do/no campo, pois a vontade do professor de que os alunos crescessem e se tornassem médicos, advogados, professores etc. expressa uma educação para o campo, ou seja, o desejo para o outro. Por outro lado, a fala dos alunos que entra em cena coloca uma educação no/do campo em atrito com este desejo para o outro. A educação no/do campo é a expressão de uma vida: "prossor prefiro a enxada a ficar aqui sentado sem fazer nada. Trator é fácil. É só pegar o prumo dele e já é”. Que matemática acontece ao pegar o prumo de um trator?!

"Vamos aos saberes locais, porque eles também foram acumulados pela humanidade”. A segunda categoria discute quais conteúdos fazem parte do componente curricular. Tal discussão argumenta sobre a escola, não somente a escola do campo, mas as escolas como um local privilegiado para o acesso ao conhecimento, de modo que não deveria excluir de seus currículos os saberes acumulados pela humanidade, mas ao contrário, deveria incluí-los. Ainda ressalta que são esses saberes locais, comumente excluídos do currículo, que devem formar a base das propostas das escolas do campo. Percebem que essa categoria converge para a primeira categoria na medida em que ambas considerarem a realidade, os saberes que são produzidos localmente, com aspecto central para currículos da escola do campo.

Esta segunda categoria, expressa o desejo de uma educação para o campo junto a uma educação no/do campo, ou seja, ela engendra as três categorias. Em outras palavras, esse engendramento seja, talvez, um possível para pensar uma educação do/no/com/para campo. Junto à fala dos alunos ao professor no episódio 4, por exemplo, os alunos expressam um desejo maior de estar no/em campo que na sala de aula, ou seja, há uma falta do campo na sala de aula. Eles repetem: "prossor prefiro a enxada a ficar aqui sentado sem fazer nada. Trator é fácil. É só pegar o prumo dele e já é [...]. Prefiro carpi o quintal de casa a vim pra cá”.

Em contrapartida a essas duas categorias, a terceira categoria, "Matemática é Matemática, ou tem Matemática do campo?” caminha por outros trieiros. Essa categoria nega que exista especificidades para realidades distintas, no caso, a camponesa, ou seja, nessa categoria há uma defesa da universalização do conhecimento, nesse caso, do conhecimento matemático. 
A quarta categoria, "A escola pode ajudar nessa formação deles, ajudar na família, no cultivo, no plantio". Trilha pelos caminhos da formação. Mais especificamente sobre a formação técnica voltada para o meio rural. Para isso discute ser necessário que haja alteração dos componentes curriculares, bem como de outros itens curriculares.

Para finalizar esta mesa com a Línlya, retornamos a uma pergunta que fizemos em algumas linhas anteriores, qual seja: que matemática acontece ao pegar o prumo de um trator?! Esta pergunta só é possível junto à fala dos alunos, "trator é fácil. É só pegar o prumo dele e já é". Em nossa leitura, a terceira categoria, que nega a possibilidade de outras matemática, é, com esta fala, é deslocada de seu lugar universal, ou seja, a fala dos alunos "destrói” o discurso legitimador uma única, e universal, matemática... Para ir, há um prumo a ser pego no trato, uma medida, uma espacialidade. Por outro lado, esta fala afirma a quarta categoria, pois os alunos provocam a existência de uma espacialidade e uma medida que não está configurada dentro da Matemática universal.

Essas vidas insistem em re-existir: "a gente sabe o que tem que saber já".

\section{Fios de territórios re-existenciais de uma pesquisa(dora)}

Caro leitor, a ficção de Lopes (2016) parece nos possibilitar isto, finalizar abruptamente, sem concluir. Ao longo do texto, operamos a ficção de uma narradora na pesquisa(dora) friccionando seus episódios e alguns fios da Educação do Campo. Agora é com vocês. Deixamos isto aberto, como começamos. Com diversos fios soltos. Um convite para que você possa estranhar a composição de um artigo em camposição. Lhe convidamos a friccionar os territórios re-existencias narrados por Lopes (2016), a urdir os fios aqui puxados, a compor uma colcha. Aqui, não buscamos o concluso, mas o in-concluso. Onde, com suas mãos, possamos compor outras linhas de inter-rupções do tempo na velocidade dos corredores que trans-bordam vidas dos territórios re-existenciais de uma pesquisa(dora) em camposição, composição. Onde acontece uma educação no/do/com/para campo no movimento dos fluxos operados no re-existir das vidas que são afirmadas. Voltando no meio, perguntamos: que educação (matemática) de/na/com/para Educação do Campo pode?

\section{Referências}

BARBOSA, L. N. S. C. DE. Entendimentos a respeito da matemática na educação do campo: questões sobre currículo. 2014. 234 f. Tese (Doutorado em Educação Matemática) Universidade Estadual Paulista "Júlio Mesquita Filho" (UNESP), Rio Claro, 2014.

BRASIL. Lei $n^{\circ}$ 9394, de 20 de dezembro de 1996. Estabelece as diretrizes e bases da educação nacional. Diário Oficial República Federativa do Brasil, Brasília, 23 dez. 1996. Disponível em:

$<$ http://pesquisa.in.gov.br/imprensa/jsp/visualiza/index.jsp?jornal=1\&pagina=1\&data=23/12/ 1996>. Acesso em: 20 setembro de 2017 
BRASIL. Ministério da Educação. Resolução $n^{\circ} 1$, de 3 de abril de 2002. Institui Diretrizes Operacionais para a Educação Básica nas Escolas do Campo. Diário Oficial

República Federativa do Brasil, Brasília, 9 abr. 2002.

BRASIL. Ministério da Educação. Resolução $n^{\circ}$ 2, de 28 de abril de 2008. Estabelece diretrizes complementares, normas e princípios para o desenvolvimento de políticas públicas de atendimento da Educação Básica do Campo. Diário Oficial República Federativa do Brasil, Brasília, 29 abr. 2008. Disponível em:

$<$ http://pesquisa.in.gov.br/imprensa/jsp/visualiza/index.jsp?data=29/04/2008\&jornal=1\&pagi na=25\&totalArquivos=96.> Acesso em: 20 de setembro de 2015.

BRASIL. Ministério da Educação. Resolução no 4, de 13 de julho de 2010. Institui Diretrizes Curriculares Nacionais Gerais para a Educação Básica. Diário Oficial República Federativa do Brasil. Brasília, 2010.

BRASIL, Ministério da Educação. Programa Nacional de Educação na Reforma Agrária PRONERA. Brasília: Ministério da Educação, 2010.

BRASIL, Ministério da Educação. Programa Nacional de Educação do Campo PRONACAMPO: documento orientador. Brasília: Ministério da Educação, 2013.

CASLELLO, L. A.; MARSICO, C. T. Oculto nas palavras: dicionário etimológico para ensinar e aprender. Tradução Ingrid Müller Xavier. Belo Horizonte: Autêntica, 2007.

DELEUZE, G. Espinosa: filosofia prática. Tradução Daniel Lins; Fabien Pacal Lins. São Paulo: Escuta, 2002.

LOPES, R. M. G. Histórias de uma pesquisa(dora) em uma escola do campo com professores que lecionam Matemática. 2016. 143 f. Dissertação (Mestrado em Educação Matemática) Universidade Estadual Paulista "Júlio Mesquita Filho" (UNESP), Rio Claro, 2016.

SOUZA, L. A. DE; SILVA, C. R. M. DA. Narrativas e História Oral: possibilidades de investigação em Educação Matemática. História da Matemática para o Ensino ed. São Paulo: Editora Livraria da Física, 2015. v. 7.

\section{SOBRE OS AUTORES}

RONILCE MAIRA GARCIA LOPES. É mestra em Educação Matemática pela Universidade Estadual Paulista "Júlio Mesquita Filho" (UNESP-Rio Claro). Atualmente é bolsista de Doutorado pela CAPES, sendo aluna do Programa de Pós-Graduação em Educação Matemática na mesma instituição. Possui Graduação em Matemática - Licenciatura pela Universidade Federal de Mato Grosso do Sul, câmpus de Paranaíba (UFMS/Cpar). Foi bolsista do Programa Institucional de Bolsas de Iniciação à Docência (PIBID). Tem pesquisado as relações entre Educação Matemática e Educação do Campo.

DIEGO DE MATOS GONDIM. Mestre em Educação Matemática pela Universidade Estadual Paulista "Júlio Mesquita Filho" (UNESP-Rio Claro). Doutorando em Educação Matemática, pela mesma instituição. Pesquisa em Educação Matemática com ênfase em Filosofia da Matemática e da Educação Matemática, História da Matemática e Etnomatemática, atuando nos seguintes temas: filosofia contemporânea francesa, formação da sociedade contemporânea, lugar-espaço-tempo, sala de aula, ensinar e aprender e... Atualmente tem focado nas produções de si (e dos comuns) pensando um lugar-espaço-tempo 
do acontecimento, que é todo coetâneo, e faz-se corpo ético e estético e político e... nas sociedades contemporâneas. 